\title{
How signaling between cells can orient a mitotic spindle
}

\author{
Adam D. Werts and Bob Goldstein \\ Biology Department, University of North Carolina at Chapel Hill, Chapel Hill NC 27599 USA
}

\begin{abstract}
In multicellular animals, cell communication sometimes serves to orient the direction in which cells divide. Control of division orientation has been proposed to be critical for partitioning developmental determinants and for maintaining epithelial architecture. Surprisingly, there are few cases where we understand the mechanisms by which external cues, transmitted by intercellular signaling, specify the division orientation of animal cells. One would predict that cytosolic molecules or complexes exist that are capable of interpreting extrinsic cues, translating the positions of these cues into forces on microtubules of the mitotic spindle. In recent years, a key intracellular complex has been identified that is required for pulling forces on mitotic spindles in Drosophila, C. elegans and vertebrate systems. One member of this complex, a protein with tetratricopeptide repeat (TPR) and GoLoco (G $\alpha$-binding) domains, has been found localized in positions that coincide with the positions of spindle-orienting extracellular cues. Do TPR-GoLoco proteins function as conserved, spatially-regulated mediators of spindle orientation by intercellular signaling? Here, we review the relevant evidence among cases from diverse animal systems where this protein complex has been found to localize to specific cell-cell contacts and to be involved in orienting mitotic spindles.
\end{abstract}

\section{Keywords}

mitotic spindle; cell division; signaling; asymmetric division; TPR; GoLoco

\section{Intercellular communication is a necessary aspect of some cell divisions in animal systems}

\subsection{Intercellular signals can guide cell division}

Cell division orientation is an important part of development and tissue maintenance [1-6]. Abnormal placement of the division plane has been recognized to disrupt cell fate specification for over 30 years [7] and has more recently been proposed to contribute to defective morphogenesis $[1,2,5]$ and cancer [8]. While cell shape has been shown to be one contributor to placement of cell division planes [9-12], recent discoveries have highlighted a role of cell signaling in spindle orientation.

Since the 1990s, it has become clear that extrinsic signals can determine the orientation in which certain cells divide. Manipulating the positions of cells and signals has revealed that

\footnotetext{
(C) 2011 Elsevier Ltd. All rights reserved.

Corresponding author: (Note: If it is possible to not indicate a corresponding author at all, we would prefer that) Bob Goldstein, Biology Department, University of North Carolina at Chapel Hill, Chapel Hill NC 27599 USA, bobg@ unc.edu, phone 919 843-8575.

Publisher's Disclaimer: This is a PDF file of an unedited manuscript that has been accepted for publication. As a service to our customers we are providing this early version of the manuscript. The manuscript will undergo copyediting, typesetting, and review of the resulting proof before it is published in its final citable form. Please note that during the production process errors may be discovered which could affect the content, and all legal disclaimers that apply to the journal pertain.
} 
the position from which an extrinsic signal is presented to a cell can determine the orientation of the cell division machinery [13-15]. These experiments make clear that extrinsic signals can function not just as simple switches that allow cells to respond to internal polarity (permissive cues), but instead can serve as important positional landmarks that determine the specific orientations of mitotic spindles (instructive cues) (Figure 1): Cells are telling their neighbors in which direction to divide.

Surprisingly, while studies of cell division orientation have been carried out for over a century [16], very little is known about how intercellular signaling leads to normal division orientation. In principle, for a cell to divide in an orientation determined by extrinsic signals, several events need to occur: 1) First, the cell needs to receive an external cue from a neighboring cell. This cue can come in multiple forms, such as a secreted molecule, like Wnt [14], or a transmembrane or adhesive molecule, such as cadherin [17]. 2) Second, the cell needs to interpret the external cue, translating its position into internal polarity. 3) Third, the internal polarity must be translated into forces on the cytoskeleton to set up a specified axis of division. 4) Lastly, the cell needs to divide. This can result in the partitioning of cell fate determinants [18], to one daughter cell.

\subsection{An example of the importance of intercellular communication for cell division orientation: the role of cadherin in the Drosophila germline}

Cell-cell signaling regulates division orientation and cell fate in the male and female germline stem cells (GSCs) in Drosophila. GSCs in the Drosophila germline receive signals from cells within the stem cell niche, aligning the mitotic spindle of the stem cell perpendicular to the area of contact with the niche. These signals come in the form of bone morphogenetic protein (BMP) from cap cells and signals for Janus kinase-signal transducers and activators of transcription (JAK-STAT) signaling from the hub cells in the female and male germline respectively. Signaling between the hub or cap cells and the GSCs controls GSC renewal [19]. In both the male and female germlines, cadherin molecules localize at the boundary of cap or hub cells and the germline stem cells, are required to maintain stem cell adhesion within the niche, and are involved in stem cell polarization and spindle orientation [20, 21]. Loss of E-cadherin in the male or female germlines results in loss of GSCs from the niche [20, 22]. In the male germline, GSC spindle orientation may be determined partly by asymmetric inheritance of mother vs. daughter centrosomes: centrosomes are segregated asymmetrically, with the mother centrosome always remaining anchored to the contact with the niche [23]. The mother centrosome is likely anchored by a physical link between astral microtubules and E-cadherin-rich adherens junctions between the stem cell and the hub cells through an APC (adenomatous polyposis coli) protein [21, 24]. In this system, it has not been shown whether E-cadherin and APC function as instructive cues for spindle orientation or whether this centrosome-anchoring phenomenon merely provides a permissive external cue to orient division in response to a separate cue. In the future, it would be interesting to determine whether GSC division is oriented by instructive or permissive cues from the hub, by experimentally repositioning the adherens junctions, possibly through cell manipulations, and assaying for re-establishment of centrosome anchoring and reorientation of the mitotic spindle of the stem cell in relation to the hub.

E-cadherin and APC have also been implicated in similar processes in other systems, namely the regulation of cell polarity [17, 25], centrosome tethering [26], and mitotic division orientation [27]. This suggests that E-cadherin-mediated polarity is one key way in which cells communicate to regulate division orientation. (For a recent review on adhesion molecules regulating stem cell division, see [28]). 


\subsection{TPR-GoLoco proteins as candidate transducers of positional information from intercellular signaling to spindle orientation}

In a wide range of animal systems, members of a conserved protein complex, the TPRGoLoco complex, are important for regulating division orientation. These systems include C. elegans embryos [29-31], Drosophila neuroblasts and sensory organ precursors [15, 3235], a variety of vertebrate epithelia [36-40], mammalian neural progenitors [41-43], mammalian T-cells [44], and gastrulating zebrafish embryos [35]. This complex was discovered independently in C. elegans embryos, Drosophila neuroblasts, and cultured mammalian cells. In the mid-1990s, heterotrimeric G-proteins were implicated in cell division orientation in C. elegans embryos, as early as the one-cell stage [45]. G $\alpha$ proteins were later found to be the relevant G-protein components [30, 46]. Heterotrimeric Gproteins were known to respond to extracellular signals, via seven-pass transmembrane receptors, so it was surprising to find a role for these proteins in the one-cell stage embryo, in a cell that has no neighbors from which to receive signals.

How might G-proteins function in the absence of cell-cell signaling at the one-cell stage? A possible solution came when receptor-independent activators of G-protein signaling (called AGS or RGS proteins) were identified [47-49]. Proteins resembling these were found in flies (a protein called Pins), worms (GPR-1/2) and mammals (LGN), and importantly, these proteins were shown to function in spindle positioning in each system [29, 50-53]. Each of these proteins has a G $\alpha$-binding "GoLoco" domain, which can displace G $\beta$ and inhibit GDP dissociation from $\mathrm{G} \alpha[54,55]$. They also have a protein-interaction domain consisting of 34amino acid repeats (tetratricopeptide repeats, or TPR; [56]) that include the LGN amino acid sequence (Leu-Gly-Asn) [57].

Together, these data established a link between plasma membrane-associated $\mathrm{G} \alpha$ proteins, the TPR-GoLoco proteins, and normal orientation of the mitotic spindle. How do these proteins affect the spindle? Is the effect direct, through microtubule-associated proteins, or indirect? It turns out that TPR-GoLoco proteins bind directly to microtubule-associated, coiled-coil proteins -- NuMA in mammalian cells, the NuMA homolog Mud in Drosophila, and a distantly-related protein LIN-5 in C. elegans [29, 50, 51, 58-60]. The TPR-GoLoco protein LGN was shown to act as a conformational switch that binds G $\alpha$ and NuMA simultaneously, providing a link from a plasma membrane-associated protein to the mitotic spindle [61]. Also associated is the microtubule motor dynein [62, 63], as well as Discslarge (Dlg; a membrane-associated guanylate kinase) and kinesin [64], or Inscuteable in some systems [53] (Figure 2).

Altogether, the data suggest that the TPR-GoLoco-containing complex serves as a connection between the plasma membrane and microtubules. Indeed, the complex is important for the formation of a mechanical link between the plasma membrane and astral microtubules: Laser-cutting experiments in C. elegans embryos have revealed cortical pulling forces on mitotic spindles [65, 66], and these forces are lost in the absence of members of the complex $[51,52,65]$. How then does the complex move a spindle to a specific site on the cortex, instead of providing similar pulling forces along the entire cell cortex? In many systems, one member of the complex is localized to a specific cortical site, and is absent or at lower levels elsewhere. In most cases, it is the TPR-GoLoco protein that is asymmetrically localized [36, 51-53, 67], although the NuMA/Mud/LIN-5 component can be asymmetrically localized as well in some systems [36, 58-60, 68]. TPR-GoLoco proteins are increasingly found with restricted localization in parts of the cell cortex in systems with medical relevance, including vertebrate lung epithelia [39, 69], neuroepithelia [40], neural progenitors [41-43], T-cells [44], and in a model for cyst formation [38]. 
How does signaling between cells orient mitotic spindles? In multiple systems, TPR-

GoLoco proteins localize in positions coincident with sites of cell contact, or where specific signals are presented, suggesting that they might be a central part of the answer. However, it is not clear in all cases whether the TPR-GoLoco proteins localize downstream of extrinsic cues, or only downstream of an intrinsic polarity (Figure 1). Here, we ask the specific question: Do the protein complexes containing TPR-GoLoco proteins serve as conserved machines that can interpret positional information from extracellular cues, and translate that information into specific spindle orientations? To address this, we discuss first the most thoroughly described examples of TPR-GoLoco protein localization and function in model systems where intercellular signaling may be involved. We end with recent discoveries from vertebrate systems and discuss the evolution of TPR-GoLoco protein functions. Throughout, we point out similarities and differences between systems, in an attempt to sample the broad range of contexts to which this complex has been adapted for orienting mitotic divisions.

\section{Drosophila sensory organ precursors: A clear connection between intercellular signaling, TPR-GoLoco protein positioning, and instructive control of spindle orientation}

In the developing Drosophila peripheral nervous system, sensory organ precursor cells (SOPs) undergo several rounds of asymmetric division, forming an external sensory organ composed of five cell types: hair, socket, neuron, sheath, and glia [70, 71]. The orientation of the initial division of the progenitor cell, called $\mathrm{pI}$, is controlled by planar cell polarity (PCP) proteins: the transmembrane proteins Frizzled (Fz) and Strabismus/Van Gogh (Stbm/ Vang; a four-pass transmembrane protein in Drosophila, also called Van Gogh-like 2 or Vangl2 in mammals [72]) $[15,73]$. In PCP, the extracellular domain of Stbm/Vang has been proposed to act as a receptor for the extracellular domain of $\mathrm{Fz}$ on neighboring cells, resulting in nonautonomous polarization of cells, with Stbm/Vang recruited to one side of each cell [73]. This interaction may be indirect, relying on homotypic interactions between two functional forms of Flamingo (Fmi) that can recruit Fz and Stbm/Vang to opposite sides of a cell boundary [74] (Figure 3A). In the sensory organ precursors, PCP proteins affect the localization of the Drosophila TPR-GoLoco protein Pins, with Pins localizing to the anterior side of the cell, where Stbm/Vang is recruited [15, 75].

In the Drosophila SOPs, Ric-8, a guanine nucleotide-exchange factor, recruits Pins by regulating the localization of its cortical tether Gai [76], while Stbm/Vang functions to refine Pins recruitment to the anterior cortex [77]. In parallel, Dsh prevents posterior cortical accumulation of Pins [77], likely by inhibition of cortical Stbm/Vang [15], resulting in restriction of the size of the cortical domain that attracts centrosomes (Figure 3A). At the anterior cortex, Pins interacts with Dlg, an interaction that is important for the anterior accumulation of both proteins [75]. Cortically localized Pins and Dlg regulate cell polarity through localization of Bazooka (Baz; PAR-3 in other systems), excluding Baz from the anterior cortex and allowing its accumulation at the posterior cortex [75] (Figure 3A and 3B). Pins and Baz contribute redundantly to spindle positioning [78]. The result of Fz-Dsh signaling and polarized Pins recruitment is an oriented spindle which is controlled in two dimensions: along the axis of anterior-posterior polarity of the tissue and within the plane of the epithelium, oblique to the apical basal axis [35, 76] (Figure 3C).

Interestingly, this is the only system to date where there is a clear connection between instructive intercellular signaling, TPR-GoLoco protein localization, and spindle orientation. The PCP protein Dsh acts downstream of Fz to restrict the size of the Pins cortical domain (Figure 3A). In some Dsh mutants, the cortical domain of Pins is expanded, and both centrosomes in the cell, rather than just one, move inappropriately toward the Pins domain 
during mitosis. This results in misoriented cell division [15]. Furthermore, moving intercellular signals by generating clones of cells that lack Stbm/Vang or that have reduced Fz results in the relocalization of cortical Pins and reorientation of the mitotic spindle. This makes clear that Pins localization responds to the position at which intercellular signaling occurs [15] (Figure 3D). These results highlight the importance of intercellular signaling as an instructive cue for localizing cortical TPR-GoLoco proteins, and they provide a template for how TPR-GoLoco proteins might function in other systems as intermediates between instructive external cues and spindle positioning.

\section{Early C. elegans development: Role of the TPR-GoLoco protein GPR-1/2 in the four-cell stage embryo}

At the four-cell stage in the C. elegans embryo, two adjacent cells signal to each other, affecting the division orientation of each cell. An endomesodermal cell called EMS, and a germline precursor cell called $\mathrm{P}_{2}$, orient their divisions toward a shared cell-cell contact [13, 79]. EMS signals to $P_{2}$ via a pathway involving MES-1 (a receptor tyrosine kinase-like transmembrane protein unique to nematodes) upstream of a Src kinase (SRC-1). $\mathrm{P}_{2}$ signals to EMS via both the MES-1 pathway and a Wnt pathway [14, 29-31, 51, 79-84]. These signaling pathways are required for normal division orientation of each cell [14, 79, 82]. Manipulating signaling-mutant cells to specific positions has demonstrated that Wntexpressing $\mathrm{P}_{2}$ cells can provide instructive cues for spindle orientation to the EMS cell [83]. MES-1, on the other hand, acts as a permissive cue in EMS --required for spindle orientation toward a site at which Wnt signaling occurs [83].

What occurs downstream of these pathways that might affect division orientation? Both MES- 1 and SRC-1 have been implicated in recruiting dynactin to the $\mathrm{P}_{2}$-EMS contact, and dynactin is required for normal EMS division orientation [31]. An enrichment of the TPRGoLoco protein pair GPR-1/2 is also observed at the $\mathrm{P}_{2}$-EMS boundary [29, 30, 51]. MES-1 signaling, but not Wnt signaling, is essential for GPR-1/2 recruitment $[29,30]$ and enrichment of phosphotyrosine at the $\mathrm{P}_{2}$-EMS contact [82]. This suggests that the local phosphorylation of some target(s) that might be involved in normal spindle alignment. However, the identity of such target(s) has yet to be determined.

While GPR-1/2 appears to be a mediator of intercellular signaling and division orientation, a direct relationship between intercellular signaling, TPR-GoLoco protein localization, and spindle orientation has yet to be clearly demonstrated in this system. With GPR-1/2 enrichment seen at a contact site between two cells, it is difficult to know if GPR-1/2 is asymmetrically localized in EMS, in $\mathrm{P}_{2}$, or in both cells. However, the majority view in the field is that GPR-1/2 cortical enrichment is involved at least in EMS division orientation [4, $29,30,85,86]$. This is based in part on evidence that inactivating one of GPR-1/2's cortical G $\alpha$ tethers, GPA-16, or inactivating a polarized, cortical GPR-1/2 antagonist, the DEPdomain protein LET-99, both result in spindle orientation defects in the EMS cell [30]. Since MES-1/SRC-1 signaling is required for both GPR-1/2 enrichment at the $\mathrm{P}_{2}$-EMS contact and normal $\mathrm{P}_{2}$ division $[79,81]$, it is possible that GPR-1/2 localization is important in the $\mathrm{P}_{2}$ cell. Indeed, our recent experiments have established that GPR-1/2 is localized dynamically and asymmetrically in $\mathrm{P}_{2}$, and that GPR-1/2 mediates mitotic spindle orientation by cell-cell signaling in $\mathrm{P}_{2}$ (Werts, Roh-Johnson and Goldstein, unpublished). The potential to move cells and signals to specific positions, and to image responses at high resolution, makes this system an especially attractive one for addressing fundamental questions in the future. 


\section{Drosophila neuroblasts: The TPR-GoLoco protein Pins orients divisions}

Drosophila neuroblasts, which are central nervous system progenitor cells, form by delamination from the neuroepithelium during embryonic development. Once delaminated, neuroblasts become polarized and undergo repeated cycles of asymmetric divisions, resulting in self-renewal of the neuroblast and the production of ganglion mother cells (for a recent review focusing on Drosophila neuroblast polarity see [87]). When mechanically dissociated from the neuroepithelia, Drosophila neuroblasts retain the ability to divide asymmetrically, albeit in random orientations with respect to previous divisions, suggesting that they can polarize in the absence of an external cue, but that the polarity is randomly established from one division to the next [88]. However, when neuroblasts remained in contact with clusters of at least two neuroepithelial cells during dissociation, cell divisions were oriented relative to the contact site [88]. This suggests that the neuroblasts orient divisions by an external cue that might function either as an instructive or permissive signal for normal spindle orientation. The identity of the relevant cell-cell signaling molecules remains unknown to date.

In Drosophila neuroblasts, Pins functions in division orientation. Pins is recruited to the apical cortex by two parallel pathways: the Inscuteable(Insc)/Par pathway [53, 67, 89], and the microtubule/Khc-73 (kinesin)/Dlg pathway [32, 64]. In the Insc/Par pathway, interactions between Pins, Insc, and Baz (a homolog of Par3) are required for asymmetric cortical localization of each protein [53, 67, 89]. Disrupting Pins, Insc, or Baz localization results in disruption of this entire protein complex, and is associated with mitotic spindle orientation defects and loss of division asymmetry [53, 67, 89]. Interestingly, unlike in Drosophila SOPs, Pins in Drosophila neuroblasts localizes with, rather than opposite, the cortical polarity protein Baz. This reversal of Pins polarity between two cell types within the same organism has been attributed to the expression of Insc, as ectopic expression of Insc in SOPs, cells in which Insc is not normally expressed, causes Pins to colocalize with Baz and reverse the polarity of the cell [75]. This further highlights the broad range of contexts in which the TPR-GoLoco protein module can be applied to spindle orientation downstream of cell interactions, even within the same organism.

In parallel to the Insc/Par pathway, the microtubule/Khc-73/Dlg pathway [32, 64] of apical Pins recruitment appears to function at metaphase to maintain linkage between the mitotic spindle and cortical polarity, possibly through interaction with proteins such as Mud and dynein [32, 64]. Pins in Drosophila neuroblasts is known to bind directly to the microtubuleassociated protein Mud, which functions similarly to C. elegans LIN-5 and mammalian NuMA, and is required for normal mitotic spindle orientation [58, 60]. Furthermore, similar to dynactin's role in orienting divisions in the four-cell stage C. elegans embryo ([31], discussed above), the Lis1/dynactin complex has been shown to regulate Drosophila neuroblast spindle orientation [34], potentially downstream of Pins and Mud [64]. Thus, these proteins may play conserved roles in different systems.

In the future, it will be interesting to identify the nature of the external cue, and determine if intercellular signaling in this system functions in an instructive or permissive manner for Pins localization and division orientation. It will also be interesting to learn if intercellular signaling orients division by similar mechanisms as in other systems, such as the cadherin adhesions in Drosophila germline stems cells, or by novel signals, such as functional homologs of C. elegans MES-1, to further understand the diversity of signaling mechanisms to which TPR-GoLoco localization has become linked through evolution. 


\section{Vertebrate cells use conserved TPR-GoLoco protein complex members to orient cell divisions}

In recent years, multiple studies have implicated the vertebrate TPR-GoLoco proteins LGN or AGS3 in normal division orientation of polarized cells in various epithelia [36-40, 69, 90, 91], neural progenitors [41-43], and possibly mammalian T-cell divisions [44]. Vertebrate TPR-GoLoco proteins localize near certain cell-cell contacts and orient divisions in multiple tissues [36-38, 40-43]. To our knowledge, there is little evidence addressing whether the localization of vertebrate TPR-GoLoco proteins at cell-cell contacts is determined by instructive, intercellular signals. Alternatively, it is possible that intrinsic polarity cues affect TPR-GoLoco protein localization, and perhaps division alignment, independent of extrinsic signals.

The mechanisms that localize the TPR-GoLoco protein LGN in mammalian epithelial cells has been studied in detail using an in vitro model, Madin-Darby Canine Kidney (MDCK) cell epithelial cyst formation. When plated in a 3D matrix, MDCK cells divide and develop into cysts of apico-basally polarized epithelial cells surrounding hollow lumens [92]. LGN localizes near cell-cell contacts within the cyst [38]. This localization may be required to orient cell divisions and maintain normal, single-lumen morphology, as disrupting LGN's cortical localization, disrupting interactions with LGN's binding partners, or artificially mistargeting LGN's cortical G $\alpha$ tether to a membrane where it is not normally enriched all result in spindle orientation defects and disorganized cysts with multiple lumens [38]. Normal LGN localization is controlled by known cell polarity proteins, Par3 and aPKC [37]. In this system, Par3 recruits aPKC, which can phosphorylate LGN on serine 401, allowing a 14-3-3 protein to inhibit LGN cortical localization by blocking phospho-LGN binding to the cortical tether, Gai, at the apical lumen [37]. This in turn enables LGN to be enriched near cell-cell contacts, a position to which mitotic spindles align [37, 38]. In this system, LGN appears to localize similarly to Pins in Drosophila SOPs: on cortical domains that have little Par3/Baz. Similarities between the two systems suggest that intercellular communication might localize LGN to orient divisions in MDCK cell cysts too, but this has yet to be tested.

Although LGN localization is aPKC-dependent in MDCK cells, this is not a hallmark of LGN localization mechanisms in all vertebrate cells. In chick neuroepithelial cells, LGN localizes to a lateral cortical belt around the cell, and is required for cell division within the plane of the epithelium [90]. In this case, apical aPKC appears to be neither necessary nor sufficient to exclude apical LGN localization: LGN still localizes to the cortex when aPKC is constitutively activated and cortically localized; an aPKC inhibitor does not prevent normal LGN localization; and mutation of serine 401 reduces, but does not mislocalize, cortical LGN asymmetry [40]. Taken together, it appears that LGN localization mechanisms are to some degree organism and cell-type specific, further highlighting the plasticity of the module through which LGN exerts its function.

Two examples from vertebrate systems suggest that LGN localization depends on extracellular cues. First, during asymmetric division in mouse neural progenitors, mice deficient in the PCP mediator Vangl2 show decreased asymmetric distribution of cortical LGN, and this is associated with altered division orientation [43]. This suggests that PCP signaling may mediate spindle orientation through localization of TPR-GoLoco-domain proteins as has been shown in Drosophila SOPs [15], however whether this signaling is instructive or permissive is unknown. In a second system, mammalian skin, there is evidence that LGN localization is mediated by extracellular signals, from both the basement membrane, and other cells [36]. Disruption of $\beta 1$ integrin, a protein essential for focal adhesions and basement membrane assembly, or disruption of $\alpha$-catenin, a component of adherens junctions between cells, causes mislocalization of LGN and spindle orientation 
defects [36]. While this suggests that the basement membrane and cell-cell contacts may contribute to positioning LGN, whether these are instructive or simply permissive cues for LGN localization remains untested.

\section{Roles for Lin-5/Mud/NuMA in spindle orientation independent of TPR- GoLoco proteins}

In several of the systems described above, localization of TPR-GoLoco proteins at specific cell-cell contacts plays an important role in normal spindle orientation. TPR-GoLoco proteins are presumed to function by recruiting binding partners to specific cortical sites, binding partners that can associate with and/or pull on microtubules. However, in some cases, it appears that the binding partners localize asymmetrically and play key roles in spindle orientation independent of TPR-GoLoco protein localization. For example, in mammalian skin, asymmetric cortical localization of LGN and its binding partner NuMA have been found in asymmetrically dividing cells [93]. However, LGN also localizes asymmetrically in some symmetrically dividing cells, without co-localization of NuMA, suggesting the existence of another NuMA localization determinant that may be important for spindle orientation [93]. Interestingly, in these symmetrically dividing cells, the spindle does not always orient in line with asymmetric LGN localization, revealing that spindle orientation can in some cases be uncoupled from asymmetric localization of LGN [93]. In a second example, the functional homolog of NuMA in C. elegans, LIN-5, has been shown to promote spindle rotation in meiosis, independent of the C. elegans TPR-GoLoco proteins GPR-1/2 and their cortical tether G [94]. Instead, LIN-5 functions in meiosis as a member of a complex involving a protein called ASPM-1 (abnormal spindle-like, microcephalyassociated protein) as well as calmodulin. Third, Drosophila Mud can function in spindle orientation with Frizzled and Dishevelled, with Mud recruited to an asymmetric cortical site by binding directly to Dishevelled [35]. This complex appears to be involved in spindle orientation in parallel to the TPR-GoLoco protein-dependent orientation pathway, and an orthologous NuMA-Dishevelled complex has been shown to function similarly in zebrafish cell division orientation [35]. Together, these experiments suggest that while TPR-GoLoco domain protein localization is a key determinant of spindle orientation in many systems, its binding partners can localize and function in spindle orientation independent of TPRGoLoco domain protein localization in some cases.

\section{Evolutionary origins}

Do TPR-GoLoco proteins function as conserved, spatially-regulated mediators of spindle orientation by intercellular signaling? Addressing the extent to which molecules and mechanisms are conserved requires some knowledge about the molecules and mechanisms of ancestral organisms. We would like to understand when these proteins first arose and what functions they had at various stages of animal evolution. The existence of proteins with TPR motifs N-terminal to GoLoco motifs in worms, flies and vertebrates suggests an ancient origin of this protein family, in early bilateral animals. At this stage in animal evolution, it is likely that TPR-GoLoco proteins functioned in mitotic spindle orientation, perhaps in response to intrinsic polarity cues, since this function is common to worms, flies and vertebrates.

We have found proteins with at least one TPR motif N-terminal to a GoLoco motif by a CDART search [95] in more distantly related animals, such as placozoans and cnidarians, and even outside of the animals, in a unicellular choanoflagellate, Salpingoeca. The presence of these proteins in the broad diversity of animals plus a choanoflagellate -thought to be a sister group to the animals [96] -- suggests that TPR-GoLoco proteins existed before bilateral animals arose, in the ancient, ancestral animals present more than 
500 million years ago. Whether TPR-GoLoco proteins functioned in spindle orientation this early is not clear. Determining whether distantly related organisms such as cnidarians or choanoflagellates use TPR-GoLoco proteins to orient mitotic spindles will help in addressing this.

When did TPR-GoLoco proteins acquire a role in mediating instructive, intercellular cues? To date, solid evidence that TPR-GoLoco proteins mediate instructive extracellular cues for spindle orientation exists only in Drosophila sensory organ precursors. In systems where there is not yet solid evidence addressing this specific point, experimentally moving the extracellular cues to new positions will make it possible to determine if this is the case. This protein family might have initially functioned in spindle orientation independently of intercellular signaling, and these proteins might have been co-opted by intercellular signaling pathways subsequently. Work toward understanding the mechanisms by which TPR-GoLoco proteins function with intercellular signaling, in diverse systems, will be important for answering the more general question of how signaling between cells can orient cell divisions in ways that can lead to normal development and tissue organization.

\section{Acknowledgments}

We thank Sophie Dal-Pra, José-Eduardo Gomes, Terry Lechler, Erin Osborne, and members of the Goldstein lab for helpful discussions and comments on the manuscript. Our work on cellular responses to signaling has been supported by an NIH Cell \& Molecular Biology Training Grant at UNC Chapel Hill, NIH grant R01-GM083071 and NSF grant IOS-0917726.

\section{References}

1. Baena-Lopez LA, Baonza A, Garcia-Bellido A. The orientation of cell divisions determines the shape of Drosophila organs. Curr Biol. 2005; 15:1640-4. [PubMed: 16169485]

2. Fischer E, Legue E, Doyen A, Nato F, Nicolas JF, Torres V, Yaniv M, Pontoglio M. Defective planar cell polarity in polycystic kidney disease. Nat Genet. 2006; 38:21-3. [PubMed: 16341222]

3. Saburi S, Hester I, Fischer E, Pontoglio M, Eremina V, Gessler M, Quaggin SE, Harrison R, Mount R, McNeill H. Loss of Fat4 disrupts PCP signaling and oriented cell division and leads to cystic kidney disease. Nat Genet. 2008; 40:1010-5. [PubMed: 18604206]

4. Segalen M, Bellaiche Y. Cell division orientation and planar cell polarity pathways. Semin Cell Dev Biol. 2009; 20:972-7. [PubMed: 19447051]

5. Karner CM, Chirumamilla R, Aoki S, Igarashi P, Wallingford JB, Carroll TJ. Wnt9b signaling regulates planar cell polarity and kidney tubule morphogenesis. Nat Genet. 2009; 41:793-9. [PubMed: 19543268]

6. Quyn AJ, Appleton PL, Carey FA, Steele RJ, Barker N, Clevers H, Ridgway RA, Sansom OJ, Nathke IS. Spindle orientation bias in gut epithelial stem cell compartments is lost in precancerous tissue. Cell Stem Cell. 2010; 6:175-81. [PubMed: 20144789]

7. Whittaker JR. Acetylcholinesterase development in extra cells caused by changing the distribution of myoplasm in ascidian embryos. J Embryol Exp Morphol. 1980; 55:343-54. [PubMed: 7373203]

8. Pease JC, Tirnauer JS. Mitotic spindle misorientation in cancer - out of alignment and into the fire. J Cell Sci. 2011; 124:1007-16. [PubMed: 21402874]

9. Symes K, Weisblat DA. An investigation of the specification of unequal cleavages in leech embryos. Dev Biol. 1992; 150:203-18. [PubMed: 1371479]

10. Rappaport R, Rappaport BN. Cleavage in conical sand dollar eggs. Dev Biol. 1994; 164:258-66. [PubMed: 8026628]

11. Tsou MF, Ku W, Hayashi A, Rose LS. PAR-dependent and geometry-dependent mechanisms of spindle positioning. J Cell Biol. 2003; 160:845-55. [PubMed: 12642612]

12. Gibson WT, Veldhuis JH, Rubinstein B, Cartwright HN, Perrimon N, Brodland GW, Nagpal R, Gibson MC. Control of the mitotic cleavage plane by local epithelial topology. Cell. 2011; 144:427-38. [PubMed: 21295702] 
13. Goldstein B. Cell contacts orient some cell division axes in the Caenorhabditis elegans embryo. J Cell Biol. 1995; 129:1071-80. [PubMed: 7744956]

14. Schlesinger A, Shelton CA, Maloof JN, Meneghini M, Bowerman B. Wnt pathway components orient a mitotic spindle in the early Caenorhabditis elegans embryo without requiring gene transcription in the responding cell. Genes Dev. 1999; 13:2028-38. [PubMed: 10444600]

15. Gomes JE, Corado M, Schweisguth F. Van Gogh and Frizzled act redundantly in the Drosophila sensory organ precursor cell to orient its asymmetric division. PLoS One. 2009; 4:e4485. [PubMed: 19214234]

16. Hertwig O. Uber den Werth der ersten Furchungszellen fur die Organbildung des Embryos. Experimentelle Studien am Frosch und Tritonei. Archiv fur mikroscopische Anatomie. 1893; 42:662-807.

17. Dupin I, Camand E, Etienne-Manneville S. Classical cadherins control nucleus and centrosome position and cell polarity. J Cell Biol. 2009; 185:779-86. [PubMed: 19487453]

18. Yan B. Numb--from flies to humans. Brain Dev. 2010; 32:293-8. [PubMed: 19380208]

19. Fuller MT, Spradling AC. Male and female Drosophila germline stem cells: two versions of immortality. Science. 2007; 316:402-4. [PubMed: 17446390]

20. Song X, Zhu CH, Doan C, Xie T. Germline stem cells anchored by adherens junctions in the Drosophila ovary niches. Science. 2002; 296:1855-7. [PubMed: 12052957]

21. Inaba M, Yuan H, Salzmann V, Fuller MT, Yamashita YM. E-cadherin is required for centrosome and spindle orientation in Drosophila male germline stem cells. PLoS One. 2010; 5:e12473. [PubMed: 20824213]

22. Voog J, D'Alterio C, Jones DL. Multipotent somatic stem cells contribute to the stem cell niche in the Drosophila testis. Nature. 2008; 454:1132-6. [PubMed: 18641633]

23. Yamashita YM, Mahowald AP, Perlin JR, Fuller MT. Asymmetric inheritance of mother versus daughter centrosome in stem cell division. Science. 2007; 315:518-21. [PubMed: 17255513]

24. Yamashita YM, Jones DL, Fuller MT. Orientation of asymmetric stem cell division by the APC tumor suppressor and centrosome. Science. 2003; 301:1547-50. [PubMed: 12970569]

25. Nejsum LN, Nelson WJ. A molecular mechanism directly linking E-cadherin adhesion to initiation of epithelial cell surface polarity. J Cell Biol. 2007; 178:323-35. [PubMed: 17635938]

26. McCartney BM, McEwen DG, Grevengoed E, Maddox P, Bejsovec A, Peifer M. Drosophila APC2 and Armadillo participate in tethering mitotic spindles to cortical actin. Nat Cell Biol. 2001; 3:933-8. [PubMed: 11584277]

27. Le Borgne R, Bellaiche Y, Schweisguth F. Drosophila E-cadherin regulates the orientation of asymmetric cell division in the sensory organ lineage. Curr Biol. 2002; 12:95-104. [PubMed: 11818059]

28. Marthiens V, Kazanis I, Moss L, Long K, Ffrench-Constant C. Adhesion molecules in the stem cell niche--more than just staying in shape? J Cell Sci. 2010; 123:1613-22. [PubMed: 20445012]

29. Srinivasan DG, Fisk RM, Xu H, van den Heuvel S. A complex of LIN-5 and GPR proteins regulates $G$ protein signaling and spindle function in C elegans. Genes Dev. 2003; 17:1225-39. [PubMed: 12730122]

30. Tsou MF, Hayashi A, Rose LS. LET-99 opposes Galpha/GPR signaling to generate asymmetry for spindle positioning in response to PAR and MES-1/SRC-1 signaling. Development. 2003; 130:5717-30. [PubMed: 14534135]

31. Zhang H, Skop AR, White JG. Src and Wnt signaling regulate dynactin accumulation to the P2EMS cell border in C. elegans embryos. J Cell Sci. 2008; 121:155-61. [PubMed: 18187449]

32. Siegrist SE, Doe CQ. Microtubule-induced Pins/Galphai cortical polarity in Drosophila neuroblasts. Cell. 2005; 123:1323-35. [PubMed: 16377571]

33. Nipper RW, Siller KH, Smith NR, Doe CQ, Prehoda KE. Galphai generates multiple Pins activation states to link cortical polarity and spindle orientation in Drosophila neuroblasts. Proc Natl Acad Sci U S A. 2007; 104:14306-11. [PubMed: 17726110]

34. Siller KH, Doe CQ. Lis1/dynactin regulates metaphase spindle orientation in Drosophila neuroblasts. Dev Biol. 2008; 319:1-9. [PubMed: 18485341] 
35. Segalen M, Johnston CA, Martin CA, Dumortier JG, Prehoda KE, David NB, Doe CQ, Bellaiche Y. The Fz-Dsh planar cell polarity pathway induces oriented cell division via Mud/NuMA in Drosophila and zebrafish. Dev Cell. 2010; 19:740-52. [PubMed: 21074723]

36. Lechler T, Fuchs E. Asymmetric cell divisions promote stratification and differentiation of mammalian skin. Nature. 2005; 437:275-80. [PubMed: 16094321]

37. Hao Y, Du Q, Chen X, Zheng Z, Balsbaugh JL, Maitra S, Shabanowitz J, Hunt DF, Macara IG. Par3 controls epithelial spindle orientation by aPKC-mediated phosphorylation of apical Pins. Curr Biol. 2010; 20:1809-18. [PubMed: 20933426]

38. Zheng Z, Zhu H, Wan Q, Liu J, Xiao Z, Siderovski DP, Du Q. LGN regulates mitotic spindle orientation during epithelial morphogenesis. J Cell Biol. 2010; 189:275-88. [PubMed: 20385777]

39. El-Hashash AH, Turcatel G, Al Alam D, Buckley S, Tokumitsu H, Bellusci S, Warburton D. Eya1 controls cell polarity, spindle orientation, cell fate and Notch signaling in distal embryonic lung epithelium. Development. 2011; 138:1395-407. [PubMed: 21385765]

40. Peyre E, Jaouen F, Saadaoui M, Haren L, Merdes A, Durbec P, Morin X. A lateral belt of cortical LGN and NuMA guides mitotic spindle movements and planar division in neuroepithelial cells. $\mathrm{J}$ Cell Biol. 2011

41. Fuja TJ, Schwartz PH, Darcy D, Bryant PJ. Asymmetric localization of LGN but not AGS3, two homologs of Drosophila pins, in dividing human neural progenitor cells. J Neurosci Res. 2004; 75:782-93. [PubMed: 14994339]

42. Sanada K, Tsai LH. G protein betagamma subunits and AGS3 control spindle orientation and asymmetric cell fate of cerebral cortical progenitors. Cell. 2005; 122:119-31. [PubMed: 16009138]

43. Lake BB, Sokol SY. Strabismus regulates asymmetric cell divisions and cell fate determination in the mouse brain. J Cell Biol. 2009; 185:59-66. [PubMed: 19332887]

44. Oliaro J, Van Ham V, Sacirbegovic F, Pasam A, Bomzon Z, Pham K, Ludford-Menting MJ, Waterhouse NJ, Bots M, Hawkins ED, Watt SV, Cluse LA, Clarke CJ, Izon DJ, Chang JT, Thompson N, Gu M, Johnstone RW, Smyth MJ, Humbert PO, Reiner SL, Russell SM. Asymmetric cell division of $\mathrm{T}$ cells upon antigen presentation uses multiple conserved mechanisms. J Immunol. 2010; 185:367-75. [PubMed: 20530266]

45. Zwaal RR, Ahringer J, van Luenen HG, Rushforth A, Anderson P, Plasterk RH. G proteins are required for spatial orientation of early cell cleavages in C. elegans embryos. Cell. 1996; 86:61929. [PubMed: 8752216]

46. Gotta M, Ahringer J. Distinct roles for Galpha and Gbetagamma in regulating spindle position and orientation in Caenorhabditis elegans embryos. Nat Cell Biol. 2001; 3:297-300. [PubMed: 11231580]

47. Siderovski DP, Hessel A, Chung S, Mak TW, Tyers M. A new family of regulators of G-proteincoupled receptors? Curr Biol. 1996; 6:211-2. [PubMed: 8673468]

48. Cismowski MJ, Takesono A, Ma C, Lizano JS, Xie X, Fuernkranz H, Lanier SM, Duzic E. Genetic screens in yeast to identify mammalian nonreceptor modulators of G-protein signaling. Nat Biotechnol. 1999; 17:878-83. [PubMed: 10471929]

49. Takesono A, Cismowski MJ, Ribas C, Bernard M, Chung P, Hazard S 3rd, Duzic E, Lanier SM. Receptor-independent activators of heterotrimeric G-protein signaling pathways. J Biol Chem. 1999; 274:33202-5. [PubMed: 10559191]

50. Du Q, Stukenberg PT, Macara IG. A mammalian Partner of inscuteable binds NuMA and regulates mitotic spindle organization. Nat Cell Biol. 2001; 3:1069-75. [PubMed: 11781568]

51. Gotta M, Dong Y, Peterson YK, Lanier SM, Ahringer J. Asymmetrically distributed C. elegans homologs of AGS3/PINS control spindle position in the early embryo. Curr Biol. 2003; 13:102937. [PubMed: 12814548]

52. Colombo K, Grill SW, Kimple RJ, Willard FS, Siderovski DP, Gonczy P. Translation of polarity cues into asymmetric spindle positioning in Caenorhabditis elegans embryos. Science. 2003; 300:1957-61. [PubMed: 12750478]

53. Schaefer M, Shevchenko A, Knoblich JA. A protein complex containing Inscuteable and the Galpha-binding protein Pins orients asymmetric cell divisions in Drosophila. Curr Biol. 2000; 10:353-62. [PubMed: 10753746] 
54. Siderovski DP, Diverse-Pierluissi M, De Vries L. The GoLoco motif: a Galphai/o binding motif and potential guanine-nucleotide exchange factor. Trends Biochem Sci. 1999; 24:340-1. [PubMed: 10470031]

55. Natochin M, Lester B, Peterson YK, Bernard ML, Lanier SM, Artemyev NO. AGS3 inhibits GDP dissociation from galpha subunits of the Gi family and rhodopsin-dependent activation of transducin. J Biol Chem. 2000; 275:40981-5. [PubMed: 11024022]

56. Sikorski RS, Boguski MS, Goebl M, Hieter P. A repeating amino acid motif in CDC23 defines a family of proteins and a new relationship among genes required for mitosis and RNA synthesis. Cell. 1990; 60:307-17. [PubMed: 2404612]

57. Mochizuki N, Cho G, Wen B, Insel PA. Identification and cDNA cloning of a novel human mosaic protein, LGN, based on interaction with G alpha i2. Gene. 1996; 181:39-43. [PubMed: 8973305]

58. Siller KH, Cabernard C, Doe CQ. The NuMA-related Mud protein binds Pins and regulates spindle orientation in Drosophila neuroblasts. Nat Cell Biol. 2006; 8:594-600. [PubMed: 16648843]

59. Izumi Y, Ohta N, Hisata K, Raabe T, Matsuzaki F. Drosophila Pins-binding protein Mud regulates spindle-polarity coupling and centrosome organization. Nat Cell Biol. 2006; 8:586-93. [PubMed: 16648846]

60. Bowman SK, Neumuller RA, Novatchkova M, Du Q, Knoblich JA. The Drosophila NuMA Homolog Mud regulates spindle orientation in asymmetric cell division. Dev Cell. 2006; 10:73142. [PubMed: 16740476]

61. Du Q, Macara IG. Mammalian Pins is a conformational switch that links NuMA to heterotrimeric G proteins. Cell. 2004; 119:503-16. [PubMed: 15537540]

62. Gonczy P. Mechanisms of asymmetric cell division: flies and worms pave the way. Nat Rev Mol Cell Biol. 2008; 9:355-66. [PubMed: 18431399]

63. Siller KH, Doe CQ. Spindle orientation during asymmetric cell division. Nat Cell Biol. 2009; 11:365-74. [PubMed: 19337318]

64. Johnston CA, Hirono K, Prehoda KE, Doe CQ. Identification of an Aurora-A/PinsLINKER/Dlg spindle orientation pathway using induced cell polarity in S2 cells. Cell. 2009; 138:1150-63. [PubMed: 19766567]

65. Grill SW, Howard J, Schaffer E, Stelzer EH, Hyman AA. The distribution of active force generators controls mitotic spindle position. Science. 2003; 301:518-21. [PubMed: 12881570]

66. Labbe JC, McCarthy EK, Goldstein B. The forces that position a mitotic spindle asymmetrically are tethered until after the time of spindle assembly. J Cell Biol. 2004; 167:245-56. [PubMed: 15492042]

67. Yu F, Morin X, Cai Y, Yang X, Chia W. Analysis of partner of inscuteable, a novel player of Drosophila asymmetric divisions, reveals two distinct steps in inscuteable apical localization. Cell. 2000; 100:399-409. [PubMed: 10693757]

68. Park DH, Rose LS. Dynamic localization of LIN-5 and GPR-1/2 to cortical force generation domains during spindle positioning. Dev Biol. 2008; 315:42-54. [PubMed: 18234174]

69. El-Hashash AH, Warburton D. Cell polarity and spindle orientation in the distal epithelium of embryonic lung. Dev Dyn. 2011; 240:441-5. [PubMed: 21246661]

70. Schweisguth F, Gho M, Lecourtois M. Control of cell fate choices by lateral signaling in the adult peripheral nervous system of Drosophila melanogaster. Dev Genet. 1996; 18:28-39. [PubMed: 8742832]

71. Roegiers F, Younger-Shepherd S, Jan LY, Jan YN. Two types of asymmetric divisions in the Drosophila sensory organ precursor cell lineage. Nat Cell Biol. 2001; 3:58-67. [PubMed: 11146627]

72. Torban E, Kor C, Gros P. Van Gogh-like2 (Strabismus) and its role in planar cell polarity and convergent extension in vertebrates. Trends Genet. 2004; 20:570-7. [PubMed: 15475117]

73. Wu J, Mlodzik M. The frizzled extracellular domain is a ligand for Van Gogh/Stbm during nonautonomous planar cell polarity signaling. Dev Cell. 2008; 15:462-9. [PubMed: 18804440]

74. Chen WS, Antic D, Matis M, Logan CY, Povelones M, Anderson GA, Nusse R, Axelrod JD. Asymmetric homotypic interactions of the atypical cadherin flamingo mediate intercellular polarity signaling. Cell. 2008; 133:1093-105. [PubMed: 18555784] 
75. Bellaiche Y, Radovic A, Woods DF, Hough CD, Parmentier ML, O’Kane CJ, Bryant PJ, Schweisguth F. The Partner of Inscuteable/Discs-large complex is required to establish planar polarity during asymmetric cell division in Drosophila. Cell. 2001; 106:355-66. [PubMed: 11509184]

76. David NB, Martin CA, Segalen M, Rosenfeld F, Schweisguth F, Bellaiche Y. Drosophila Ric-8 regulates Galphai cortical localization to promote Galphai-dependent planar orientation of the mitotic spindle during asymmetric cell division. Nat Cell Biol. 2005; 7:1083-90. [PubMed: 16228010]

77. Bellaiche Y, Beaudoin-Massiani O, Stuttem I, Schweisguth F. The planar cell polarity protein Strabismus promotes Pins anterior localization during asymmetric division of sensory organ precursor cells in Drosophila. Development. 2004; 131:469-78. [PubMed: 14701683]

78. Cai Y, Yu F, Lin S, Chia W, Yang X. Apical complex genes control mitotic spindle geometry and relative size of daughter cells in Drosophila neuroblast and pI asymmetric divisions. Cell. 2003; 112:51-62. [PubMed: 12526793]

79. Arata Y, Lee JY, Goldstein B, Sawa H. Extracellular control of PAR protein localization during asymmetric cell division in the C. elegans embryo. Development. 2010; 137:3337-45. [PubMed: 20823070]

80. Thorpe CJ, Schlesinger A, Carter JC, Bowerman B. Wnt signaling polarizes an early C. elegans blastomere to distinguish endoderm from mesoderm. Cell. 1997; 90:695-705. [PubMed: 9288749]

81. Berkowitz LA, Strome S. MES-1, a protein required for unequal divisions of the germline in early C. elegans embryos, resembles receptor tyrosine kinases and is localized to the boundary between the germline and gut cells. Development. 2000; 127:4419-31. [PubMed: 11003841]

82. Bei Y, Hogan J, Berkowitz LA, Soto M, Rocheleau CE, Pang KM, Collins J, Mello CC. SRC-1 and Wnt signaling act together to specify endoderm and to control cleavage orientation in early $\mathrm{C}$. elegans embryos. Dev Cell. 2002; 3:113-25. [PubMed: 12110172]

83. Goldstein B, Takeshita H, Mizumoto K, Sawa H. Wnt signals can function as positional cues in establishing cell polarity. Dev Cell. 2006; 10:391-6. [PubMed: 16516841]

84. Walston T, Tuskey C, Edgar L, Hawkins N, Ellis G, Bowerman B, Wood W, Hardin J. Multiple Wnt signaling pathways converge to orient the mitotic spindle in early $\mathrm{C}$. elegans embryos. Dev Cell. 2004; 7:831-41. [PubMed: 15572126]

85. Galli M, van den Heuvel S. Determination of the cleavage plane in early C. elegans embryos. Annu Rev Genet. 2008; 42:389-411. [PubMed: 18710303]

86. Rose, LS.; Basham, SE. Encyclopedia of Life Sciences. 2006. Caenorhabditis elegans embryo: establishment of asymmetry.

87. Prehoda KE. Polarization of Drosophila neuroblasts during asymmetric division. Cold Spring Harb Perspect Biol. 2009; 1:a001388. [PubMed: 20066083]

88. Siegrist SE, Doe CQ. Extrinsic cues orient the cell division axis in Drosophila embryonic neuroblasts. Development. 2006; 133:529-36. [PubMed: 16396904]

89. Parmentier ML, Woods D, Greig S, Phan PG, Radovic A, Bryant P, O'Kane CJ. Rapsynoid/partner of inscuteable controls asymmetric division of larval neuroblasts in Drosophila. J Neurosci. 2000; 20:RC84. [PubMed: 10875939]

90. Morin X, Jaouen F, Durbec P. Control of planar divisions by the G-protein regulator LGN maintains progenitors in the chick neuroepithelium. Nat Neurosci. 2007; 10:1440-8. [PubMed: 17934458]

91. Williams SE, Beronja S, Pasolli HA, Fuchs E. Asymmetric cell divisions promote Notchdependent epidermal differentiation. Nature. 2011; 470:353-8. [PubMed: 21331036]

92. McAteer JA, Evan AP, Gardner KD. Morphogenetic clonal growth of kidney epithelial cell line MDCK. Anat Rec. 1987; 217:229-39. [PubMed: 3578840]

93. Poulson ND, Lechler T. Robust control of mitotic spindle orientation in the developing epidermis. J Cell Biol. 2010; 191:915-22. [PubMed: 21098114]

94. van der Voet M, Berends CW, Perreault A, Nguyen-Ngoc T, Gonczy P, Vidal M, Boxem M, van den Heuvel S. NuMA-related LIN-5, ASPM-1, calmodulin and dynein promote meiotic spindle rotation independently of cortical LIN-5/GPR/Galpha. Nat Cell Biol. 2009; 11:269-77. [PubMed: 19219036] 
95. Geer LY, Domrachev M, Lipman DJ, Bryant SH. CDART: protein homology by domain architecture. Genome Res. 2002; 12:1619-23. [PubMed: 12368255]

96. Carr M, Leadbeater BS, Hassan R, Nelson M, Baldauf SL. Molecular phylogeny of choanoflagellates, the sister group to Metazoa. Proc Natl Acad Sci U S A. 2008; 105:16641-6. [PubMed: 18922774] 


\section{Highlights}

- Mitotic spindles of animal cells are sometimes oriented by signals from other cells

- Proteins with TPR and GoLoco domains have conserved roles in regulating spindle orientation

- TPR-GoLoco protein localization in multiple systems suggests roles downstream of intercellular signaling 


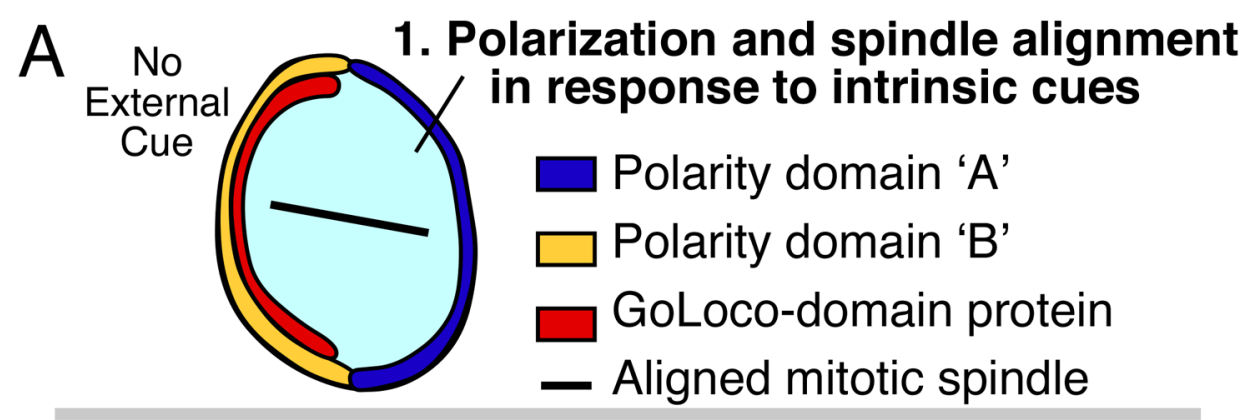

B
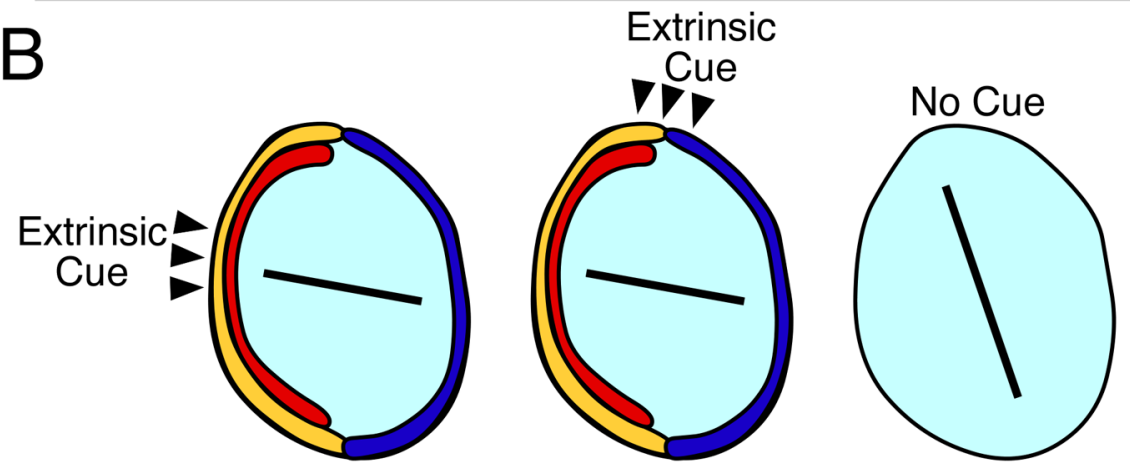

\section{Polarization and spindle alignment in response to a permissive external cue}

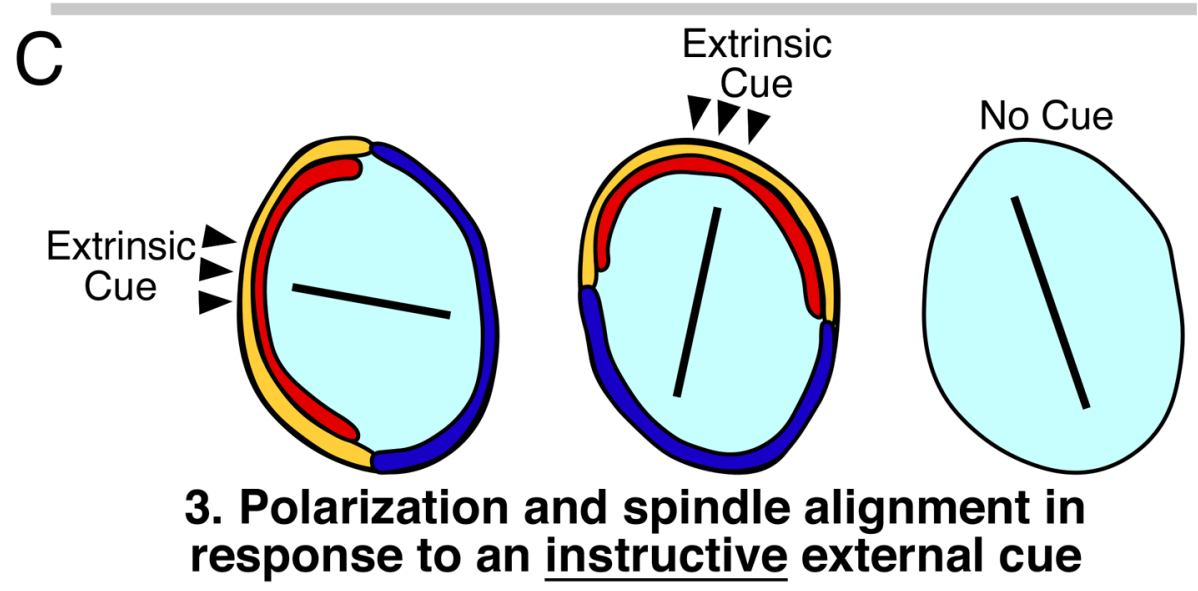

Figure 1. Polarity establishment by intrinsic cues, permissive external cues, and instructive external cues

(A) Some cells align their mitotic spindles independent of external signaling cues.

Polarity domains 'A' and 'B' are nonspecific and could represent 'Anterior' and 'Posterior' polarity, 'Apical' and 'Basal' polarity, 'Dorsal' and 'Ventral' polarity, etc, depending on the specific cell type.

(B) Permissive external cues: Some cells require an external cue (black arrowheads) for polarization and spindle alignment, but the position of that cue does not convey positional information to cell polarity: moving the cue has no effect on cell polarity or spindle orientation (middle). Absence of these cues leads to polarity defects and defects in spindle orientation (right).

(C) Instructive external cues: Some cells are polarized by instructive external cues (black arrowheads), where changing the position of the cue changes the orientation of polarity and 
division. Experimentally moving the position of an extrinsic cue differentiates between permissive (B) and instructive (C) functions in spindle orientation. 
Pulling Force on Microtubules GoLoco-domain protein complex

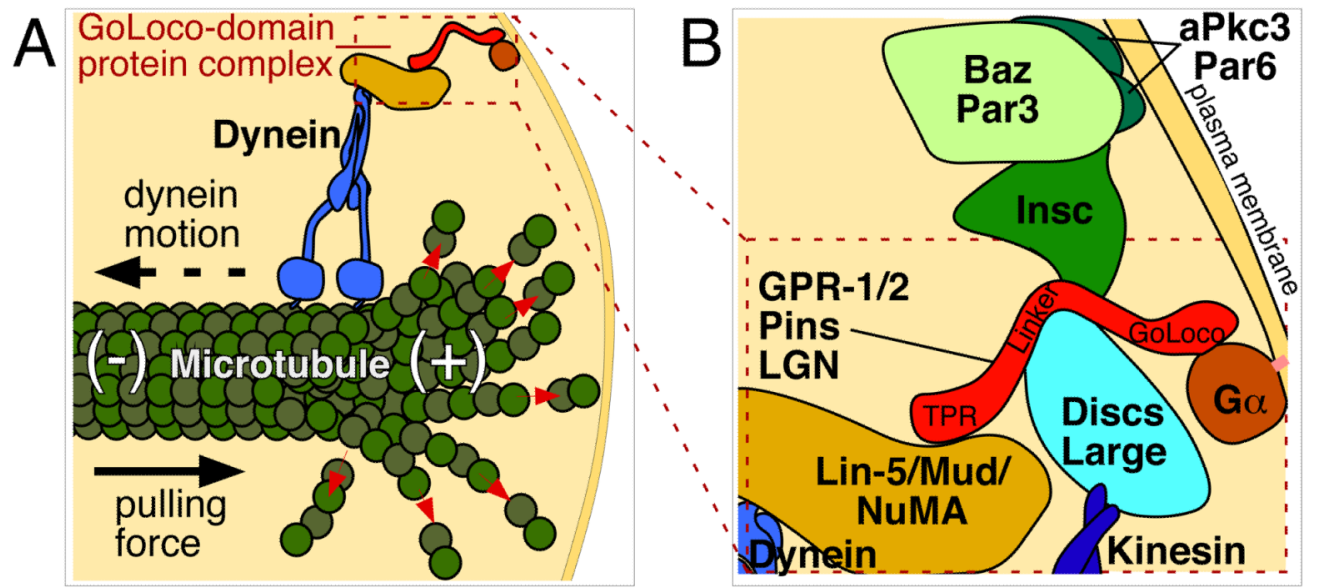

Figure 2. Model of the TPR-GoLoco protein complex

(A) Schematic showing how the TPR-GoLoco protein complex forms a link between microtubules and the plasma membrane, based upon [62]. Red arrows show tubulin depolymerization from the plus end of the microtubule. Proteins are depicted roughly proportional to their relative sizes.

(B) Enlargement of part of (A), with additional associated proteins included. See text for details. $\mathrm{G} \alpha$ is myristoylated (pink line), associating it with the plasma membrane.

Inscuteable links Par3/Baz to TPR-GoLoco proteins in some cells such as Drosophila neuroblasts [53], but this interaction is absent in cells such as MDCK cyst cells and Drosophila SOPs, where Par3/Baz localizes in a reciprocal cortical pattern to TPR-GoLoco protein $[37,75]$. 


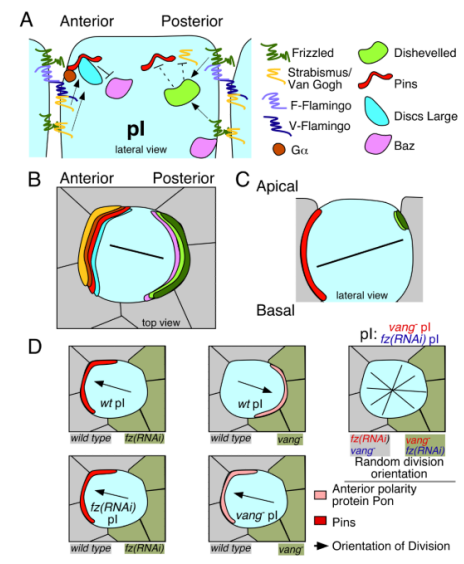

Figure 3. Intercellular signaling functions as an instructive cue for spindle orientation mediated by the TPR-GoLoco protein Pins in Drosophila SOP cells

(A) Extracellular signals from Frizzled, Strabismus, and Flamingo control Pins cortical localization and cell polarity of $\mathrm{pI}$, the primary progenitor of the sensory organ lineage. See text for details. Two functional isoforms of Flamingo have been proposed: F-Flamingo and V-Flamingo [48]. F-Flamingo is proposed to interact with and be induced by Frizzled in the same cell, while V-Flamingo is proposed to interact with Vang in the same cell [74].

(B-C) Schematics after $[35,76]$. (B) A view from the embryo's surface of an SOP cell. Colored crescents represent polarized localization of proteins shown in (A), using the same colors. (C) Schematic of localization of the relevant cortical proteins controlling division along the axis of polarity and within the plane of the epithelium. Black lines represent the orientation of the mitotic spindle.

(D) Schematic of SOP clone border analysis from experiments described in [15]. Loss of Fz or Vang on one side of a SOP cell results in altered polarization of Pins and another anterior cortical protein called Partner of Numb (Pon), and alignment of the mitotic spindle. Black arrows represent spindle alignment, and crossed black lines on the far right panels represent randomization of the division axis in the absence of external cues. SOPs in the far right two panels still polarize and divide asymmetrically in the absence of PCP signaling, but in a random orientation. 